\title{
Identified Olfactory Ensheathing Cells Transplanted into the Transected Dorsal Funiculus Bridge the Lesion and Form Myelin
}

\author{
Masanori Sasaki, ${ }^{1,2}$ Karen L. Lankford, ${ }^{1,2}$ Micheas Zemedkun, ${ }^{1,2}$ and Jeffery D. Kocsis ${ }^{1,2}$ \\ ${ }^{1}$ Department of Neurology and Center for Neuroscience and Regeneration Research, Yale University School of Medicine, New Haven, Connecticut 06510, \\ and ${ }^{2}$ Rehabilitation Research Center, Veterans Affairs Medical Center, West Haven, Connecticut 06516
}

Olfactory ensheathing cells (OECs) prepared from the olfactory bulbs of adult transgenic Sprague Dawley (SD) rats expressing green fluorescent protein (GFP) were transplanted into a dorsal spinal cord transection lesion of SD rats. Five weeks after transplantation, the cells survived within the lesion zone and oriented longitudinally along axons that bridged the transection site. Although the highest density of GFP cells was within the lesion zone, some cells distributed longitudinally outside of the lesion area. Myelinated axons spanning the lesion were observed in discrete bundles encapsulated by a cellular element. Electron micrographs of spinal cords immunostained with an anti-GFP antibody indicated that a majority of the peripheral-like myelinated axons were derived from donor OECs. Open-field locomotor behavior was significantly improved in the OEC transplantation group. Thus, transplanted OECs derived from the adult olfactory bulb can survive and orient longitudinally across a spinal cord transection site and form myelin. This pattern of repair is associated with improved locomotion.

Key words: tissue culture; implant; neuropathy; spinal; sprouting; transplant

\section{Introduction}

Adult olfactory receptor neurons continually undergo turnover from an endogenous progenitor pool, and their nascent axons grow through the olfactory nerves and cross the PNS-CNS interface, where they form new synaptic connections in the olfactory bulb (Graziadei et al., 1978). A specialized glial cell, the olfactory ensheathing cell (OEC), is associated with olfactory receptor neurons from their peripheral origin to their central projection in the outer nerve layer of the olfactory bulb (Doucette, 1991). This apparent support role of OECs in axonal growth in the adult CNS has spawned extensive research to study the potential of OEC transplants to encourage axonal regeneration and functional recovery in spinal cord injury models (Li et al., 1997, 1998; RamonCueto et al., 1998, 2000; Imaizumi et al., 2000a,b).

Transplantation of OECs into spinal cord injury models mediates some degree of axonal regeneration and functional improvement even when transplantation is delayed (Lu et al., 2002; Keyvan-Fouladi et al., 2003). Myelinated axons spanning the lesion site have a characteristic peripheral pattern of myelination

\footnotetext{
Received May 24, 2004; revised Aug. 16, 2004; accepted Aug. 16, 2004.

This work was supported in part by the Medical Research and the Rehabilitation Research Services of the Department of Veterans Affairs, the National Multiple Sclerosis Society, and the National Institutes of Health. We thank Heather Mallozzi and Margaret Borelli for technical expertise in immunohistochemistry and behavioral testing and Dr. Karen Hudman for assistance with the statistical analyses.

Correspondence should be addressed to Dr. Jeffery D. Kocsis, Department of Neurology, Yale University School of Medicine, Neuroscience Research Center, 127A, Veterans Affairs Medical Center, West Haven, CT 06516. E-mail: jeffery.kocsis@yale.edu.

DOI:10.1523/JNEUROSCI.1998-04.2004

Copyright $\odot 2004$ Society for Neuroscience $\quad$ 0270-6474/04/248485-09\$15.00/0
}

similar to that of Schwann cell (SC) myelination (Li et al., 1997, 1998; Imaizumi et al., 1998, 2000a).

Spinal cord injuries without OEC transplants can show limited SC-like myelination, presumably from invasion of the injury site from endogenous SCs (Brook et al., 1998; Imaizumi et al., 2000a,b; Namiki et al., 2000; Takami et al., 2002) or possibly from precursor cells. The degree to which OECs can integrate into injury sites and survive and whether they form myelin or facilitate endogenous myelin repair mechanisms is controversial. Takami et al. (2002) reported that SC but not OEC transplantation results in improved hindlimb locomotor function. Moreover, although numerous reports suggest that OECs can form myelin when transplanted into the demyelinated (Franklin et al., 1996; Imaizumi et al., 1998; Barnett et al., 2000; Kato et al., 2000; Akiyama et al., 2004; Radtke et al., 2004) or injured (Li et al., 1997, 1998; Imaizumi et al., 2000a,b) spinal cord, a recent study was unable to find evidence of OEC myelination in the compressed spinal cord and suggests that OEC transplantation may facilitate endogenous SC invasion into the lesion site (Boyd et al., 2004). OECs in culture are diverse and exhibit characteristics of astrocytes, SCs, and oligodendrocytes. Moreover, they express a number of trophic factors, transcription factors, and extracellular matrix molecules (Ramon-Cueto and Avila, 1998; Chuah and West, 2002; Au and Roskams, 2003) that could facilitate endogenous cell invasion, as well as angiogenesis and activation of progenitor cells.

In the present study, we transplanted OECs prepared from adult green fluorescent protein (GFP)-expressing transgenic rats into a dorsal funiculus transection model in the rat. Immuno- 
staining for GFP coupled with electron microscopy allowed ultrastructural identification of GFP myelin-forming cells. We report that transplanted OECs integrate into the injury site of a dorsal funiculus transection, distribute and associate longitudinally with axons spanning the lesion site, and form myelin. This set of anatomic events is associated with improved hindlimb locomotor function.

\section{Materials and Methods}

Isolation and characterization of donor OECs. Freshly isolated donor OECs were obtained using an exacting procedure that relies on differential dissociation and attachment rates of subtypes of cells to serially remove other cell types and obtain a highly pure population of OECs. Olfactory bulbs were removed from 4- to 8-week-old transgenic rats expressing GFP ("green rat" CZ-004, SD-Tg(Act-EGFP)CZ-004Osb; SLC, Shizuoka, Japan) and dissected free of meninges. The caudal onethird of the bulb was removed and discarded along with as much white matter as possible to isolate the outer nerve layer. The tissue was minced finely with a pair scalpel blades (\#10) on culture plastic. Nonadherent pieces of tissue were washed from the culture dish and incubated for 25 min in collagenase A $(0.75 \mathrm{mg} / \mathrm{ml}$; Roche, Indianapolis, IN), collagenase $\mathrm{D}(0.75 \mathrm{mg} / \mathrm{ml}$; Roche), and papain $(12 \mathrm{U} / \mathrm{ml}$; Worthington, Lakewood, $\mathrm{NJ}$ ) in calcium-free complete saline solution with trace cysteine for 25 min at $37^{\circ} \mathrm{C}$ on a rotary shaker in a $\mathrm{CO}_{2}$ incubator. Tissue was then centrifuged for $7 \mathrm{~min}$ at $300 \times \mathrm{g}$, the supernatant was discarded, and tissue was dissociated in $2 \mathrm{ml}$ of DMEM (Invitrogen, Carlsbad, CA) with $10 \%$ FCS using very gentle mechanical trituration first with a $5 \mathrm{ml}$ culture pipette and then with two fire-polished silicone-coated pasture pipettes with successively reduced diameters. The volume of media was immediately increased to $20 \mathrm{ml}$, and undissociated pieces of tissue were allowed to settle for 2 min before transferring the cell suspension to another culture tube and centrifuging as before. Cells were washed twice, resuspended, and preplated for $1 \mathrm{hr}$ in a culture flask at $37^{\circ} \mathrm{C}$ in a $\mathrm{CO}_{2}$ incubator. Nonadherent cells were gently washed off with DMEM, and cells were centrifuged and resuspended three times in DMEM before counting and concentrating cells to $3.0 \times 10^{4}$ cells $/ \mu \mathrm{l}$ just before transplantation.

Immediately after transplantations were completed, the remaining OECs were resuspended in $10 \mathrm{ml}$ of culture media, washed, and plated in 8-well poly-L-lysine-coated chamber slides in DMEM with 10\% FCS and penicillin-streptomycin. After 3-7 d, cells were fixed for $10 \mathrm{~min}$ in icecold methanol and incubated in primary antibody overnight at $4^{\circ} \mathrm{C}$. The antibodies used were rabbit anti-p75 (1:1000; Chemicon, Temecula, CA), mouse monoclonal anti-S100 (1:1000; Chemicon), rabbit anti-cow S100 (1:400; Dako, Carpinteria, CA), and mouse monoclonal anti-GFAP (1:1000, SMI22; Sternberger Monoclonals, Lutherville, MD). The primary antibodies were visualized with Alexa Fluor 488 goat anti-mouse (1:1000; Molecular Probes, Eugene, OR) and Alexa Fluor 594 goat antirabbit (1:1000; Molecular Probes) secondary antibodies for $6 \mathrm{hr}$ at room temperature on a shaker and counterstained with Hoechst 33358 (1: 1000; Molecular Probes) for $1 \mathrm{hr}$ at room temperature on a shaker. Random areas in each well were photographed at appropriate wavelengths with a Spot camera (Diagnostic Instruments, Sterling Heights, MI) and Spot Advanced software. The percentages of p75-, S100-, and GFAPpositive cells were counted in merged photographs with Hoechst nuclear staining.

Dorsal funiculus transection. Experiments were performed in accordance with National Institutes of Health guidelines for the care and use of laboratory animals, and the Yale University Institutional Animal Care and Use Committee approved all animal protocols. Adult female Sprague Dawley rats (150-179 gm) were anesthetized with ketamine/xylazine (90/4 mg/kg, i.p.). Under sterile technique, a T9 laminectomy was performed, and dura was opened to expose the spinal cord. The dorsal vein of the spinal cord was coagulated, and the dorsal funiculus was transected (Neumann and Woolf, 1999) using an ophthalmic scalpel (P-715; Feather Safety Co., Osaka, Japan). The overlying muscles and skin were closed in layers with 4-0 nylon sutures, and the animal was allowed to recover on a $37^{\circ} \mathrm{C}$ heating pad. This surgery resulted in paresis of the hindlimbs in all animals subjected to the procedure but did not impair eating, drinking, or elimination.

OEC transplantation. Immediately after transection of the dorsal funiculus, freshly isolated OECs derived from adult GFP-expressing rats, or vehicle alone (DMEM), were injected into the dorsal funiculus using a drawn glass micropipette. Two injections were made just rostral and two just caudal to the lesion at depths of 0.7 and $0.4 \mathrm{~mm}$, and an additional cell injection was made within the transection site for a total of five injections. The injection volume was $1.0 \mu \mathrm{l}$ per site. The OEC concentration was $3.0 \times 10^{4}$ cells $/ \mu$ l for a total of $1.5 \times 10^{5}$ cells transplanted per rat. The animals were prepared for histological study at 5 weeks after transplantation.

Immunohistochemistry procedures. Animals were perfused transcardially with PBS, followed by $4 \%$ paraformaldehyde in PBS. Cryostat sections $(25 \mu \mathrm{m})$ of spinal cord were incubated with antibodies against neurofilament (NF; 1:1000; Sigma, St. Louis, MO) and fibronectin (FN; 1:200; Molecular Probes), or P0 (protein 0) (1:150; obtained from Dr. Juan Archelos, University of Graz, Graz, Austria). Sections were then washed in PBS and incubated with appropriate secondary antibodies comprising goat anti-mouse IgG-Alexa Fluor 594 (1:1000; Molecular Probes) and donkey anti-chicken rhodamine (1:100; Chemicon) in blocking solution for $2 \mathrm{hr}$, washed in PBS, and mounted on slides. Control experiments that included the omission of primary or secondary antibodies showed no staining. The sections were examined by confocal microscopy (Nikon Eclipse E600 microscope; Simple PCI software; Compix Inc., Imaging Systems, Cranberry Township, PA) or with conventional fluorescence microscopy (Nikon Eclipse 800; Spot RT Color CCD camera; Diagnostic Instruments).

Immuno-electron microscopy. Animals were perfused transcardially with PBS, followed by $4 \%$ paraformaldehyde- $0.02 \%$ glutaraldehyde in PBS. Spinal cords were dissected, postfixed overnight in $4 \%$ paraformaldehyde, and embedded in 3\% agar for vibratome sectioning. Freefloating sections ( $150 \mu \mathrm{m}$ thick) were preincubated with $2 \%$ normal goat serum for $30 \mathrm{~min}$. Vibratome sections were collected from the lesion zone, and GFP cells were identified by fluorescence microscopy. For immunoperoxidase staining, the sections were incubated with rabbit anti-GFP antibody (1:2000; Chemicon) overnight at $4^{\circ} \mathrm{C}$. The sections were incubated in the Vectastain anti-rabbit ABC Elite kit (Vector Laboratories, Burlingame, CA) for $1 \mathrm{hr}$ at room temparature according to the manufacturer's instructions. The sections were postfixed with $1 \%$ osmium tetroxide for $4 \mathrm{hr}$, dehydrated in graded ethanol solutions, and embedded in Epox-812 (Ernest Fullam, Latham, NY). Thin plastic sections were cut on an ultramicrotome and counterstained with uranyl and lead salts and examined with an EM902A electron microscope (Zeiss, Oberkochen, Germany) operating at $80 \mathrm{kV}$.

Morphometric analysis. Spinal cords were fixed, blocked, and embedded as described previously (Lankford et al., 2002). One-micrometer semithin plastic sections were collected at $0.25 \mathrm{~mm}$ intervals through the lesion. Axon counts and cross-sectional area measurements were obtained in the dorsal corticospinal tract (dCST) and dorsal column (DC) 2 $\mathrm{mm}$ rostral and caudal to the midpoint of the lesion using a Nikon Microphot micoroscope $(100 \times)$ and image analysis software (Bioquaont Novaprime). Hand counts were performed for axons within the lesion site. Measurements were made in two defined fields $(50 \times 37 \mu \mathrm{m})$, positioned centrally in the dCST or the DC for the intact, sham injection, and transplantation groups.

One-way ANOVA was conducted, followed by a Dunnett's test to identify specific pairwise differences between the means. Comparison analyses were conducted using SPSS version 10.1.3.

Open-field locomotor testing. Behavioral analysis was performed on the OEC transplanted group $(n=20)$ and the DMEM-injected group $(n=$ 6). Preoperative testing began $2 \mathrm{~d}$ before injury and was performed weekly for 5 weeks after surgery. Locomotor function was recorded by an observer blinded using the Basso, Beattie, and Bresnahan (BBB) locomotor rating scale (Basso et al., 1995) to ensure reliability of hindlimb somatosensory testing and to assess treatment outcome. The MannWhitney $U$ test was performed for between-group comparison for BBB analysis. 
A

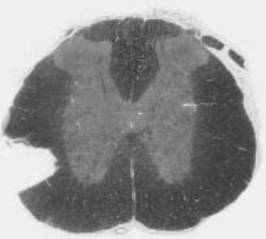

B
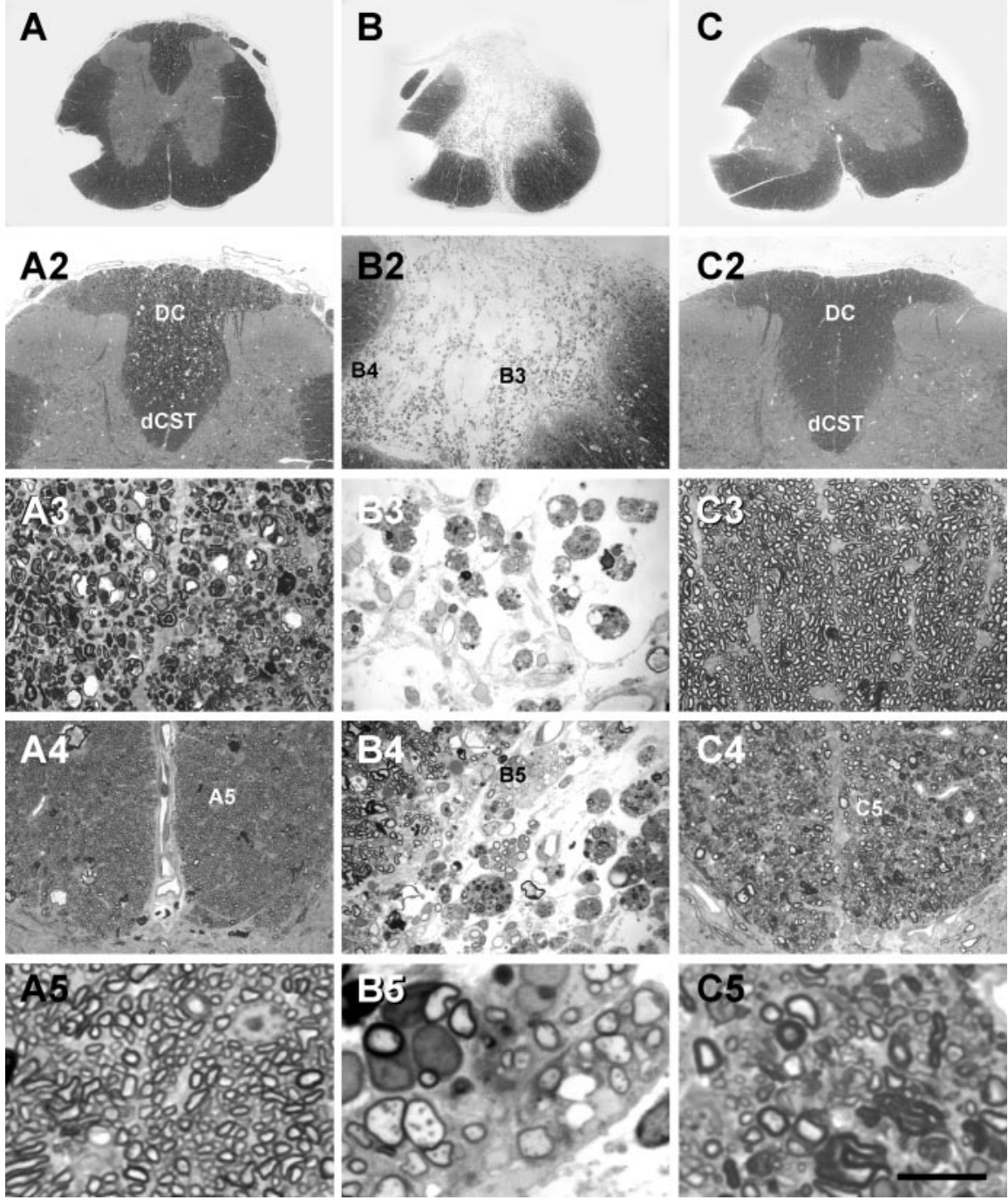

Figure 1. Cross sections (semithin plastic sections stained with methylene blue/Azure II) of spinal cord rostral to $(A)$, at the level of $(B)$, and distal to $(C)$ the transection site ( 5 weeks after injury). Rostral to the lesion, extensive axonal degeneration was observed in the dorsal columns (DC; $A 3)$ but not in the $\mathrm{d} C S T(A 4, A 5)$. Axonal degeneration was extensive in the transection site $(B 2, B 3)$, but at the edge of the lesion $(B 4, B 5)$, a modest number of axons with a peripheral pattern of myelination was observed. Caudal to the transection site, $D C$ axons were intact $(C 2, C 3)$ but $\mathrm{dCST}$ axons were in various stages of degeneration $(C 4, C 5)$. Scale bar: (in C5) A-C, $1.0 \mathrm{~mm} ; A 2-C 2,0.4 \mathrm{~mm} ; A 3-C 3, A 4-C 4,40 \mu \mathrm{m} ; A 5-C 5,8.5 \mu \mathrm{m}$.
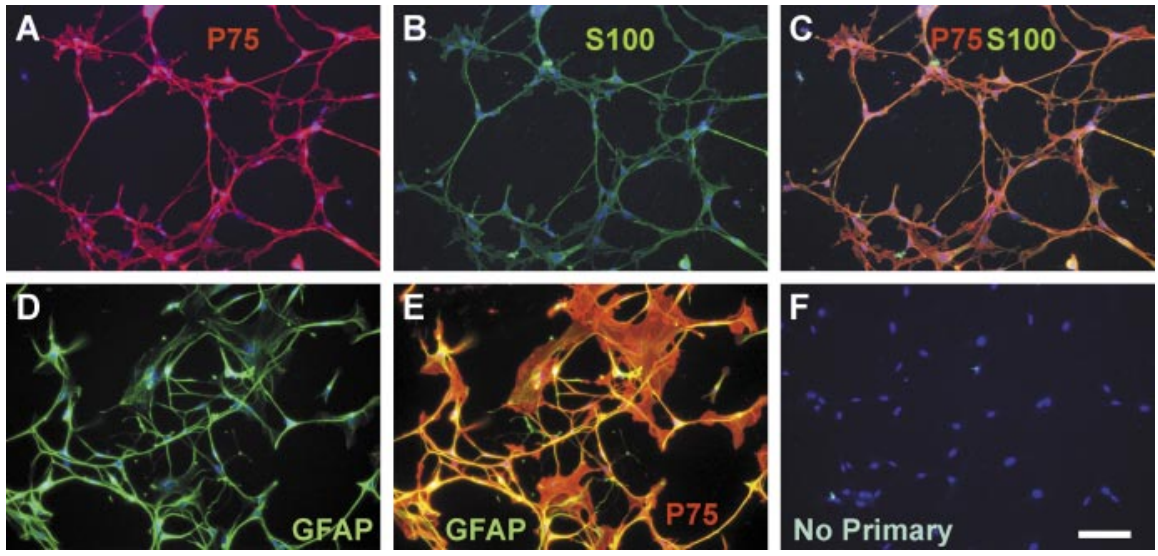

Figure 2. OECs in culture (7 d) with nuclear staining (Hoechst) and immunostained for p75 $(A)$, S100 $(B)$, and GFAP $(D)$. Merged images of $\mathrm{S} 100(C)$ and GFAP $(E)$ immunostaining with $\mathrm{p} 75$ indicated extensive colocalization, $>95 \%$ of $\mathrm{p} 75^{+}$and $S 100^{+} . F, A$ control section with nuclear staining and secondary antibody but no primary antibody. Scale bar: (in $\left.F\right) A-F, 100 \mu \mathrm{m}$.

\section{Results}

Histology of dorsal funiculus in control and transected spinal cord

The extent of the dorsal funicular lesion can be seen in $1 \mu \mathrm{m}$ plastic methylene blue/ Azure II-stained sections (Fig. 1B,B2). In sham injection rats (5 weeks after transection), the central core of the lesion site was essentially devoid of axons and composed of phagocytic cells (Fig. 1B3). However, on the outer margins of the lesion, small clusters of myelinated axons were observed (Fig. 1B5), and many had characteristic properties of peripheral-like myelination (i.e., large cytoplasmic and nuclear regions surrounding the myelinated axons). Rostral ( $2 \mathrm{~mm}$ ) to the lesion (Fig. $1 \mathrm{~A}$ ), severe axon damage was observed in the ascending DC axons (Fig. $1 A 2, A 3)$ but not in the descending dCST axons (Fig. 1A4,A5). Caudal (2 mm) to the lesion (Fig. $1 C$ ), the DC axons were preserved (Fig. 1C3), but severe axon pathology was observed in the dCST (Fig. 1C4,C5). Some large myelinated axons were observed in the dCST caudal to the lesion site as reported previously (Warden et al., 2001). These axons were generally larger than in intact animals; the mean cross-sectional area of these residual axons was $0.58 \pm 0.03 \mu \mathrm{m}^{2}(n=$ 11) compared with $0.29 \pm 0.01 \mu \mathrm{m}^{2}(n=4)$ for the intact dCST.

\section{Characterization of OECs}

After cell transplantation, the remaining OECs in the cell suspension were immediately prepared for tissue culture. They attached and spread out slowly on poly-Llysine-coated chamber slides. By day 3, the predominant cell morphology was spindle shaped, although some flattened fibroblastlike and astrocyte-like morphologies were also observed. Immunostaining coupled with Hoechst counterstaining of nuclei consistently showed that at least $95 \%$ of cells in 3-7 d cultures expressed both p75 and S100 antigens and variable numbers of cells expressed GFAP (Fig. 2).

Distribution of transplanted GFPexpressing OECs within the spinal cord Five weeks after OEC transplantation, the distribution of the GFP transplanted cells was examined in sagittal frozen sections of the spinal cord. The cells survived and distributed extensively within the transection site and more limitedly beyond the lesion site (Fig. 3A). Higher-power micrographs (Fig. $3 B$ ) show that the OECs oriented longitudinally with periodic bulbous regions of intense green fluorescence (Fig. $3 B$ ). The elongated processes showed intense fluorescence on their outer margins and low fluorescence at the core of the process. 
Nodal-like regions were observed as thin breaks between adjacent green cell regions (Fig. 3C, arrow). Confocal images from sections within the lesion zone and immunostained for NF (red) indicate the intimate association of axons with the donor GFP-expressing OECs (Fig. 3D). These axonal and GFP-associated clusters were at the center of the lesion zone that showed a paucity of axons in the sham control.

Methylene blue/Azure II semithin plastic sections through this region of the lesion 5 weeks after transplantation revealed greater structural detail. As reported initially by Li et al. (1997), small groups of myelinated axons were often surrounded by a nonmyelinating cell forming tube-like structures around the myelinated axons. This organization is not observed after endogenous repair or after transplantation of SCs (Imaizumi et al., 2000a). These profiles were observed in both dorsal (Fig. $4 A, B 1$ ) and ventral (Fig. $4 A, B 2$ ) regions of the lesion zone. Electron micrographs further indicate that the myelinated axons in the lesion zone are surrounded by cytoplasmic extensions of cells forming tunnels (Fig. 4D1,D2). These clusters of myelinated axons were variable from animal to animal and confined mostly to and near the lesion zone. FN immunoreactivity was observed throughout the central core of the lesion where GFP-expressing OECs were present (Fig. 5A-F). FN has an apparent extracellular localization (Fig. $5 E$ ) as well as some association with GFPexpressing donor cells (Fig. $5 F$ ). Rings of $\mathrm{P} 0$ labeling were observed in some regions of the lesion and were often associated with GFP cellular elements (Fig. 5G-I). In two transplanted animals from which $\mathrm{P} 0$ immunostaining was performed, axons were counted from a section in the center of the lesion to estimate the number of $\mathrm{GFP}^{+}$profiles that were associated with $\mathrm{P0}$ rings. Of the $81 \mathrm{P} 0$ identified rings, 34 $(42 \%)$ were associated with $\mathrm{GFP}^{+}$profiles, $42(52 \%)$ were not, and $5(6 \%)$ could not be identified.

\section{Immuno-electron microscopy of GFP-expressing OECs forming myelin}

Electron microscopic (EM) examination of anti-GFP immunoperoxidase-reacted sections revealed that many detectable $\mathrm{GFP}^{+}$ cells were in direct contact with host axons. Reaction product was clearly evident in the cytoplasm of many cells that formed well defined multi-laminate structures characteristic of myelin (Fig. 6). In a longitudinal section of a myelinated axon, intense reaction product can be seen in the cytoplasm of the myelin-forming cell (Fig. 6A1,A2; arrows). Large cytoplasmic and nuclear regions (Fig. 6A1) as well the presence of basal lamina and extracellular fibrils (Fig. 6B1) indicate a peripheral pattern of myelination. Some unlabeled cells forming peripheral-like myelin could also be detected within transplanted lesions in the same areas as the labeled cells (Fig. 6A1,A2,C1,C2; arrowheads). A limited number of $\mathrm{GFP}^{+}$cells surrounded host axons but did not form myelin (Fig. 6D).

We attempted to establish a first approximation of the relative contribution of donor cell to host cell myelination by counting the number of $\mathrm{GFP}^{+}$and $\mathrm{GFP}^{-}$myelinated axon profiles in a region of an OEC transplanted lesion that had a relatively large number of myelinated axons. Extensive quantification with this method is not practical because of the technical difficulties associated with the method (see Discussion). However, counts were obtained from the lesion center of a single transplant animal. Of the 193 axons in this region, we identified a total of $131 \mathrm{GFP}^{+}$ cells. Of these $\mathrm{GFP}^{+}$cells, two (slightly $<2 \%$ ) showed no direct contact with axons. The myelin-forming status of $18 \mathrm{GFP}^{+}$cells (14\%) could not be determined because of poor membrane preservation. Of the $118 \mathrm{GFP}^{+}$cells with a status that could be identified, 74 cells $(57 \%)$ showed distinct myelin structure. The re- 

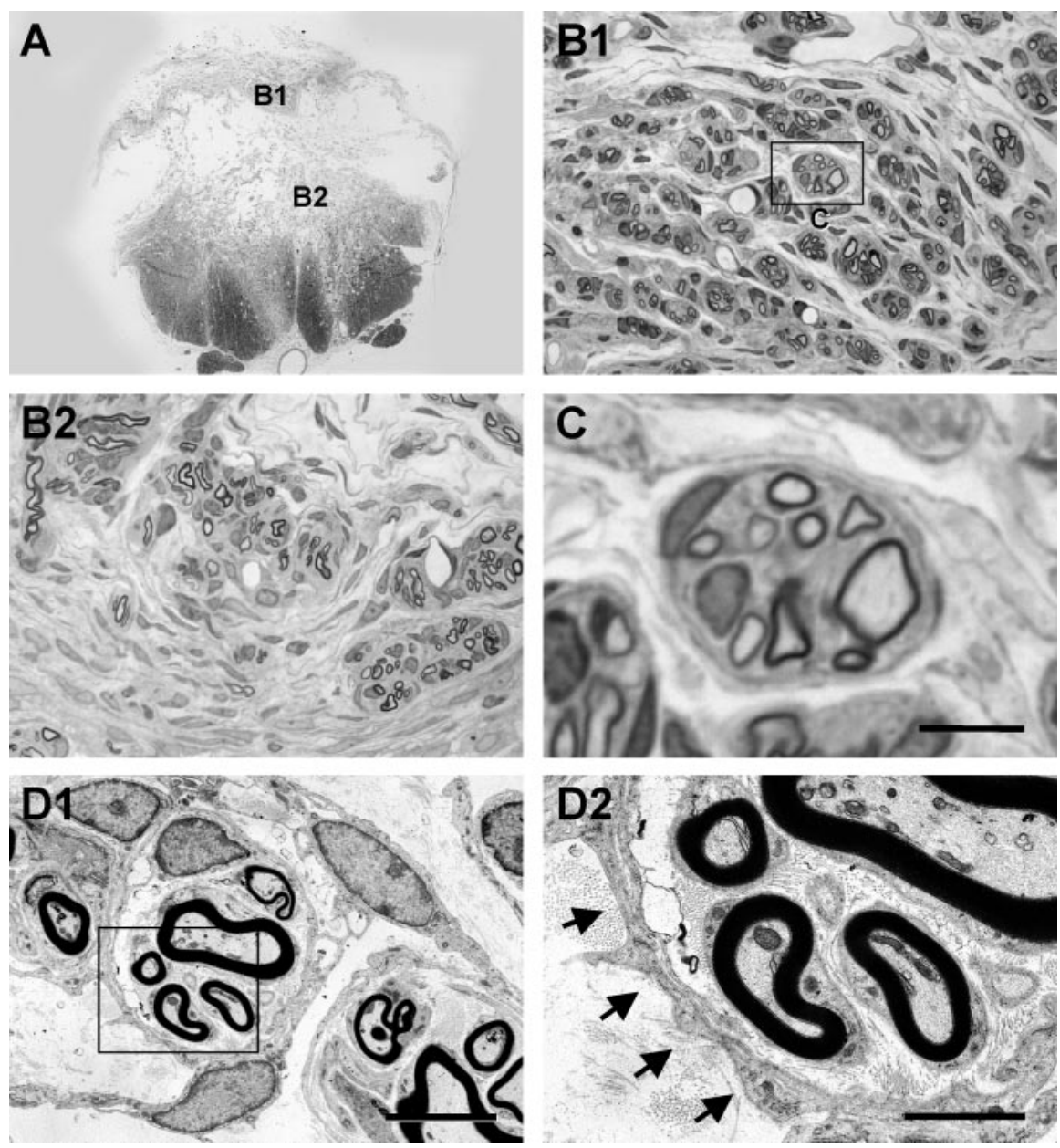

Figure 4. Semithin plastic sections stained with methylene blue/Azure Il through the transection site 5 weeks after transplantation of $\mathrm{OECS}$. A, Low-power micrograph showing completeness of the transection through the entire dorsal funiculus and beyond. $B 1, B 2$, Higher-power micrographs showing groups of myelinated axons within the lesion zone obtained from regions indicated in $A$. C, Higher-power micrograph from boxed region in B1. Note the clustering of myelinated axons surrounded by a cellular element. D1, Electron micrograph from the same lesion showing myelinated axons surrounded by a cellular element forming a tunnel. D2, Boxed region from D1. Arrows point to the cytoplasmic region of the cell surrounding the bundle of myelinated axons. Scale bars: $A, 0.75 \mathrm{~mm} ; B 1, B 2,30 \mu \mathrm{m} ; C, 6 \mu \mathrm{m} ; D 1,5 \mu \mathrm{m} ; D 2,2 \mu \mathrm{m}$.

maining $37 \mathrm{GFP}^{+}$cells (28\%) appeared to be in varying stages of wrapping or engulfing the axons but did not show distinct compact myelin. Within this same region, 62 myelinated axon profiles were detected in which they associated with myelin-forming cells that did not contain DAB reaction product. Thus, of the 136 axons that displayed compact myelin, $54 \%$ were $\mathrm{GFP}^{+}$and $46 \%$ were $\mathrm{GFP}^{-}$. These data are in general agreement with the P0 immunostaining data in which approximately half of the myelin profiles were $\mathrm{GFP}^{+}$.

\section{Morphometric analysis}

In the lesion center, a very small number of myelinated axons was detected in the sham injection group ( $64 \pm 32 ; n=7)$, but more myelinated axons were observed in the OEC transplant group $(244 \pm 50 ; n=5)$. Axons were counted from single sections at the specified regions and repeated for multiple animals $(n)$ and then averaged. Axon counts were also obtained in defined central regions of the DC and the dCST at $2 \mathrm{~mm}$ rostral and $2 \mathrm{~mm}$ caudal to the lesion. In both the sham injection and OEC transplant groups, there was extensive axon loss in the DC rostral to the lesion, but not caudal (Fig. 7A). A modest reduction in axons was observed in the dCST rostral to the lesion for both the sham injection and OEC transplant groups. However, the axon number was significantly higher in the dCST caudal to the lesion in the OEC transplant group (Fig. 7A). These observations are consistent with expected anterograde degeneration of distal cut axons and some retrograde degeneration. OEC transplants showed greater numbers of axons in the dCST at $2 \mathrm{~mm}$ caudal to the lesion. Myelinated axon counts obtained from a standardized $50 \times 36 \mu \mathrm{m}$ field in the central region of the dCST, $2.0 \mathrm{~mm}$ caudal to the lesion, indicated an increase in axon number from $145 \pm 16(n=6)$ in the sham injection group to $338 \pm 48(n=15)$ in the OEC transplant group $(p<0.005)$ compared with $878 \pm 16(n=8)$ in normal (intact) rats.

Improved hindlimb locomotor function All animals exhibited a gradual improvement in hindlimb locomotor function during the 5 week recovery period (Fig. $7 B)$. The sham injection group recovered to a BBB score of $\sim 9$ and did not display weight-bearing plantar stepping. However, the OEC transplant group recovered to $\sim 18$ on the BBB score and displayed consistent weight-bearing plantar stepping. Statistical analysis indicated that the open-field locomotor scores at 3, 4, and 5 weeks after injury and OEC transplantation was significantly higher than sham injection.

\section{Discussion}

A large body of work supports the proposal that transplantation of OECs into various spinal cord injury and demyelination models can promote axonal regeneration, remyelination, and functional recovery (Franklin et al., 1996; Li et al., 1997, 1998; Ramon-Cueto et al., 1998, 2000; Imaizumi et al., 2000a,b; Lu et al., 2002; Keyvan-Fouladi et al., 2003; Plant et al., 2003). Yet, there is an important controversy as to whether the transplanted OECs associate with axons and form peripheral myelin or whether they recruit endogenous SCs that form myelin (Takami et al., 2002; Boyd et al., 2004). OECs can express a number of trophic factors, transcription factors, and extracellular matrix molecules (Ramon-Cueto and Avila, 1998; Chuah and West, 2002; Au and Roskams, 2003; Ramer et al., 2004) that could facilitate endogenous SC cell invasion, angiogenesis, and activation of progenitor cells to facilitate repair. It is clear that some degree of SC invasion associated with axonal repair can occur, and enhancement of this process might facilitate functional recovery. In the present study, we report that transplanted GFP-expressing OECs derived from adult rat olfactory bulb survive for at least 5 weeks (study period) within the lesion zone, associate longitudinally with axons spanning the lesion, and on an ultrastructural level are associated with myelin-forming cells. These findings do not negate the possibility that endogenous SC invasion is facilitated by the OEC grafts but 
rather indicate that the donor OECs are capable of forming myelin. Indeed, we identified $\mathrm{GFP}^{-}$cells that were associated with myelinated axons in the lesion zone.

Other supportive evidence for the myelinating potential of the OECs is derived from studies using the X-irradiation/ ethidium bromide (X-EB) model of persistent demyelination in the spinal cord (Franklin et al., 1996; Imaizumi et al., 1998; Barnett et al., 2000; Kato et al., 2000; Akiyama et al., 2004). In the transection model used in the present study, the lesions were more complex and axon profiles through the lesion zone were less numerous than in the demyelinating $\mathrm{X}-\mathrm{EB}$ lesion. However, $\mathrm{GFP}^{+}$myelinating profiles could readily be recognized and were associated with NF identified axons on a light microcopic level and GFP immunoreactivity on an ultrastructural level.

A unique feature of presumptive axonal regeneration after OEC transplantation is the occurrence of groups of axons within the transection lesion site with a peripheral pattern of myelination surrounded by a fibroblast-like cell that forms a "tunnel" around small clusters of myelinated axons (Li et al., 1997). These tunnels have not been reported after SC transplantation into transection lesions (Imaizumi et al., 2000a,b) or into demyelinating lesions (Lankford et al., 2002). Li et al. (1998) referred to the surrounding fibroblast-like cells as " $\mathrm{A}$ " cells and the myelin-forming cells as " $\mathrm{S}$ " cells and suggested that both can be derived from the donor OECs. Whereas transplanted SCs can myelinate spinal cord axons (Blakemore and Crang, 1985; Baron-Van Evercooren et al., 1992; Honmou et al., 1996) and are associated with improved functional outcome (Takami et al., 2002), the A and S cell organization appears to be unique to OEC transplantation ( $\mathrm{Li}$ et al., 1997, 1998; Imaizumi et al., 2000a,b). However, Boyd et al. (2004) did not find LacZ-expressing S cells after transplantation of embryonic day 18-derived OECs into a spinal cord compression injury model but only LacZ-expressing fibroblast-like cells. They concluded that only the fibroblast-like cell is derived from the OEC transplantation and that the $\mathrm{S}$ cells are derived exclusively from invading SCs.

We found clear qualitative evidence of GFP immunoreactivity on an ultrastructural level in the cytoplasm of cells within the lesion site that were forming peripheral-like myelin. Staining of intracellular antigens for EM analysis involves a compromise between structural preservation and antibody penetration, and the amount of usable samples with this method is limited. However, in an area in which numerous myelin profiles were observed on an EM level, there was a relatively high proportion of DABpositive cells associated with myelinated axon profiles; over half of the myelinated profiles were associated with $\mathrm{GFP}^{+}$cells. It is possible that some myelin-forming cells that did not contain $\mathrm{DAB}$ reaction product were, in fact, false negatives caused by incomplete permeablization and poor penetration of antibodies, but it seems likely that both host and donor cells contribute significantly to myelination of lesioned axons.

These data indicate that transplantation of adult OECs prepared at relatively high purity $\left(>95 \% \mathrm{p}^{+} 5^{+}\right)$and not maintained in culture for extensive periods are able to form peripheral-like myelin around axons spanning a dorsal funiculus transection. Boyd et al. (2004) raised the possibility that failure of the fetalderived OECs to myelinate axons in vivo may result from LacZ expression, or its protein product $\beta$-galactosidase, interfering with myelin synthesis, although they argued against this possibility. There are, however, questions on efficiency of transfection and stability of the transfection procedure that could limit detection. GFP expression in the cells used in the present study is robust and highly distributed in the cytoplasm of these cells.

A difficulty in comparing results from OEC transplantation studies from various laboratories is that differences are present in the age of the animals used for cell harvesting, purification procedures, and lesion models into which the cells were transplanted. OECs used in the present study were prepared relatively acutely from the outer nerve layer of the adult olfactory bulb, an area rich in OECs in vivo (Devon and Doucette, 1992). The degree of cell purity $(>95 \%)$ in our cell suspension as assessed using p75/S100 immunostaining was about the same as in other studies in which immunopanning techniques were used (Takami et al., 2002; Lakatos et al., 2003) or in which OECs were prepared from embryonic tissue (Devon and Doucette, 1992). Mitotic inhibitors 

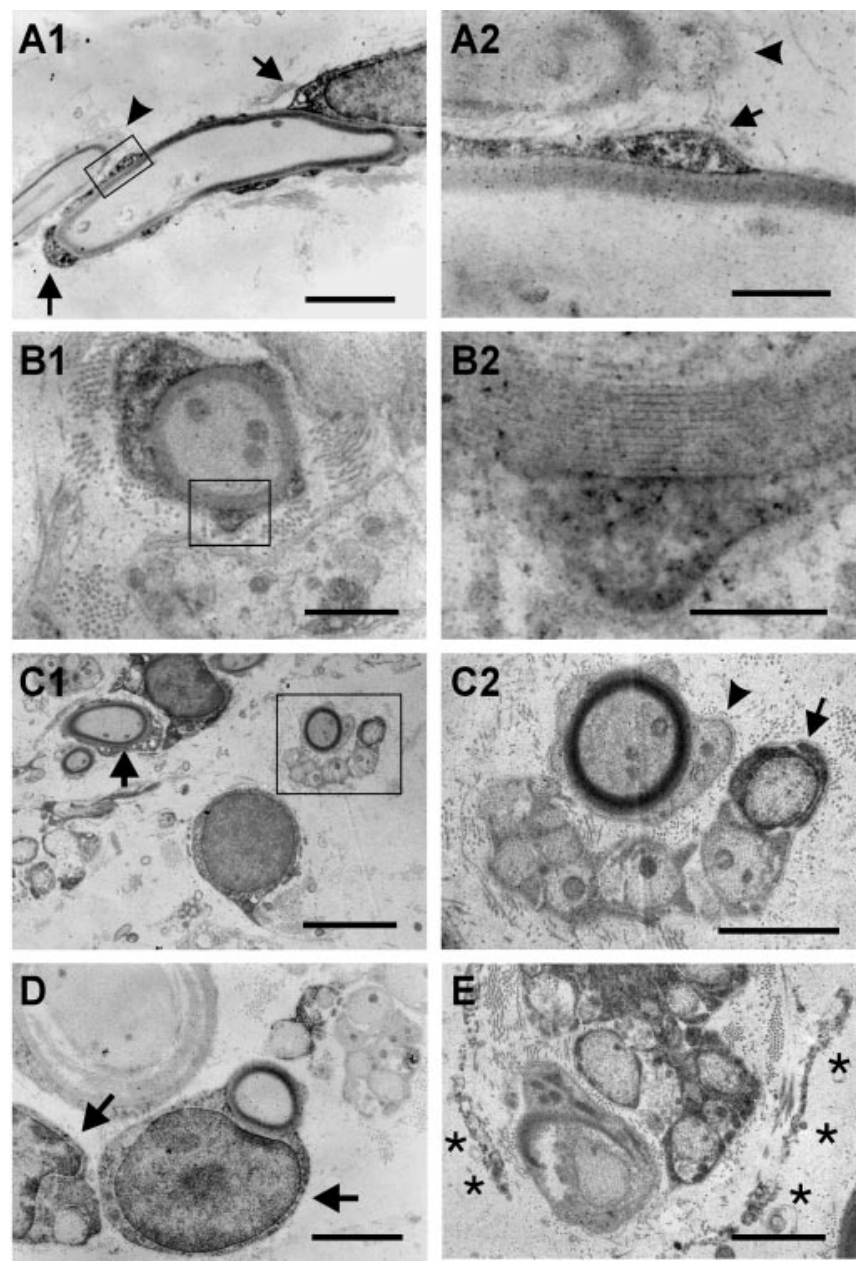

Figure 6. Electron micrographs of anti-GFP immunoperoxidase staining of OEC transplant. A1, Reaction product can be seen in cytoplasmic regions of the myelin-forming cell (arrows) but not in the myelin. A nonlabeled myelinated axon (arrowheads) is seen next to the labeled axon. The boxed area in $A 1$ is shown in $A 2 . B 1$, A cross-cut section of another axon showing cytoplastic reaction product. Enlargement of the boxed area is shown in $B 2$. Note the presence of extracellular fibrous elements in B1. C1, Field showing GFP ${ }^{+}$and GFP ${ }^{-}$myelinated axons. (2, Enlargement of the boxed area in $\mathrm{C}^{\text {. Note the GFP }}{ }^{-}$myelinated axon (arrowhead) and the axon associated with $\mathrm{GFP}^{+}$cytoplasmic processes that are not forming myelin (arrow). D, Two adjacent GFP ${ }^{+}$cells, one forming myelin (right) and one surrounding an axon without myelin formation (left). $E, A$ cluster of GFP ${ }^{+}$cells associated with axons. The asterisks indicate GFP ${ }^{+}$ processes surrounding the cluster reminiscent of an $A$ cell. Scale bars: $A 1, C 1,5 \mu \mathrm{m} ; A 2, C 2, D, E$, $2 \mu \mathrm{m} ; B 1,1 \mu \mathrm{m} ; B 2,0.25 \mu \mathrm{m}$.

and stimulators of cell proliferation and differentiation were used in those studies. In our cell preparation method from adult tissue, we did not use mitotic inhibitors, nor did we stimulate proliferation and differentiation in vivo. Contamination by SCs, which are also $\mathrm{p} 75 / \mathrm{S} 100$ positive, in our cultures would be problematic in the interpretation that adult OECs are able to form peripherallike myelin. However, one would expect, at best, a very minor contamination of SCs possibly associated with blood vessel innervation (Takami et al., 2002) or meningeal cells (Lakatos et al., 2003). Such minor contamination could not account for the vast majority (>95\%) of our cells displaying a p75/S100 phenotype.

In the present study, we focused on myelination of axons and the distribution of donor cells and not on axonal regeneration per se. Although we attempted to completely transect the dorsal funiculus, there is the prospect that some residual axons may be present. GFP donor cells were abundant within the lesion zone and extended variable degrees outside of the transection zone.
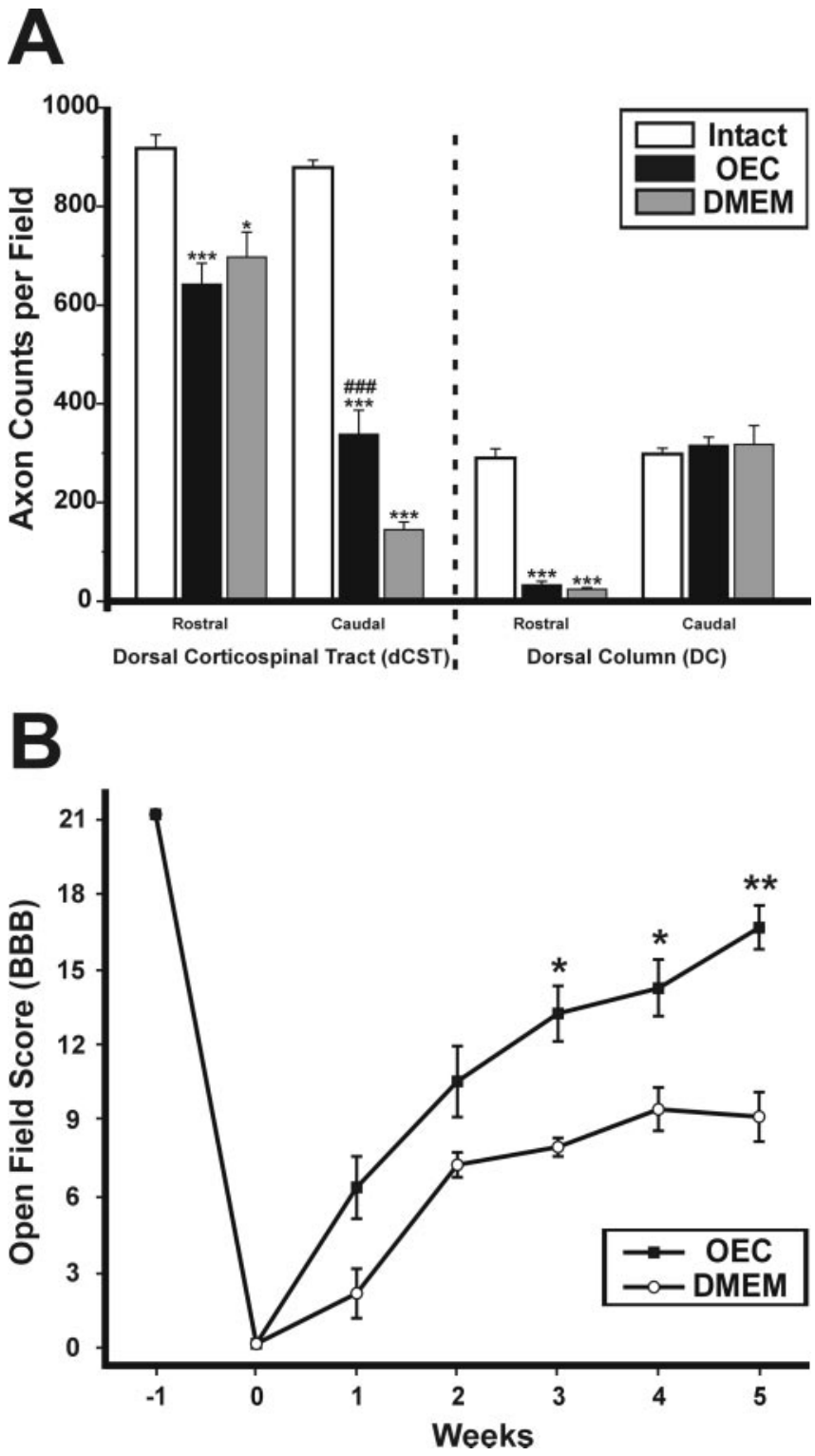

Figure 7. Axon counts of dCST and dorsal columns (DC) rostral and caudal to the lesion for the intact (control), OEC transplant, and DMEM sham injection groups ( $A$ ). Counts were obtained from a standardized microscopic field $(50 \times 35 \mu \mathrm{m})$ in the central regions of the tracts. A modest reduction in axon number is observed in the dCST rostral to the lesion in both the OEC transplants and sham injection groups. The sham injection group had a marked reduction in $\mathrm{dCST}$ axon density caudal to the lesion site, but the reduction was less for the OEC transplants. Axons in the $D C$ were substantially reduced rostral to the lesion for both $0 E C$ transplant and sham injection groups, but no difference was observed caudal to the lesion for both groups compared with control. The $n$ values (number of animals) for each group were 4, 14, 6, 8, 15, 6, $4,10,6,8,10$, and 6 from left to right, respectively. B, Open-field locomotor scores for OEC transplant $(n=20)$ and sham injection $(n=6)$ groups tested 1 week before and for 5 weeks after transplantation. One-way ANOVA (F test significant at $p<0.05$ ), followed by a Dunnett's test to identify specific pairwise differences between the means for the $0 E C$ transplant and the control groups and the sham control (DMEM) and control groups, is shown. The asterisks refer to comparison between intact control animals and the experimental groups, and the pound signs refer to the significance between the DMEM and OEC groups. The significance levels were ${ }^{*} p<$ $0.05,{ }^{* *} p<0.01,{ }^{* * *} p<0.005$, and ${ }^{\# \# \#} p<0.005$. All values are given as means $\pm S E M$.

Thus, much of the cellular matrix within the "repair" zone was derived from donor cells. GFP did not colocalize with NF staining but rather was observed in cells that associated with axons. This supports the hypothesis (Li et al., 1997) that OECs may provide a cellular matrix to promote axonal regeneration or sprouting or to remyelinate residual axons. 
Open-field locomotor behavior as scored on the BBB scale was significantly improved in the OEC transplantation group. The mechanisms for the functional improvement are not clear and have been suggested to include long tract regeneration ( $\mathrm{Li}$ et al., 1997; Ramon-Cueto et al., 2000), axonal sparing and neuroprotection (Plant et al., 2003), sprouting and plasticity associated with novel polysynaptic pathways (Keyvan-Fouladi et al., 2002), recruitment of endogenous SCs (Takami et al., 2002; Boyd et al., 2004), and remyelination (Franklin et al., 1996; Imaizumi et al., $2000 a, b)$. OECs secrete a number of trophic factors that could contribute to these events (Woodhall et al., 2001). It is possible that a set of these mechanisms is operative. Our behavioral analysis was performed for 5 weeks, so although we show significant shortterm functional improvement, longer-term behavioral studies will be necessary to assess long-term functional improvement.

OECs have emerged as an important cell candidate for cell transplantation strategies to improve functional outcome in adult spinal cord injury. Clinical investigations in spinal cord injury using OEC engraftment are in progress (Senior, 2002; Huang et al., 2003). Although it is generally agreed that under appropriate cell preparation and transplantation conditions that functional outcome can be enhanced by OEC transplantation, questions still remain with regard to the in vivo fate of transplanted OECs. In the present study, OECs survived for the 5 week study period, integrated within and spanned the transection lesion site, and robustly associated with axons forming myelin with at least a subpopulation of these axons. Whether this myelination contributes to the observed functional recovery is uncertain. The relative contribution of cellular repair versus trophic support for endogenous recruitment of cells, neuroprotection, and synaptic plasticity by OECs will be important for a comprehensive evaluation of the potential therapeutic efficacy of OECs as a cell therapy in spinal cord injury. Moreover, as our understanding of potential trophic influences of OECs is expanded, this could suggest novel pharmacological approaches to the treatment of spinal cord injury.

\section{References}

Akiyama Y, Lankford KL, Radtke C, Greer CA, Kocsis JD (2004) Remyelination of spinal cord axons by olfactory ensheathing cells and Schwann cells derived from a transgenic rat expressing alkaline phosphatase marker gene. Neuron Glia Biol 1:1-9.

Au E, Roskams AJ (2003) Olfactory ensheathing cells of the lamina propria in vivo and in vitro. Glia 41:224-236.

Barnett SC, Alexander CL, Iwashita Y, Gilson JM, Crowther J, Clark L, Dunn LT, Papanastassiou V, Kennedy PG, Franklin RJ (2000) Identification of a human olfactory ensheathing cell that can effect transplant-mediated remyelination of demyelinated CNS axons. Brain 123:1581-1588.

Baron-Van Evercooren A, Gansmuller A, Duhamel E, Pascal F, Gumpel M (1992) Repair of a myelin lesion by Schwann cells transplanted in the adult mouse spinal cord. J Neuroimmunol 40:235-242.

Basso DM, Beattie MS, Bresnahan JC (1995) A sensitive and reliable locomotor rating scale for open field testing in rats. J Neurotrauma 12:1-21.

Blakemore WF, Crang AJ (1985) The use of cultured autologous Schwann cells to remyelinate areas of persistent demyelination in the central nervous system. J Neurol Sci 70:207-223.

Boyd JG, Lee J, Skihar V, Doucette R, Kawaja MD (2004) LacZ-expressing olfactory ensheathing cells do not associate with myelinated axons after implantation into the compressed spinal cord. Proc Natl Acad Sci USA 101:2162-2166.

Brook GA, Plate D, Franzen R, Martin D, Moonen G, Schoenen J, Schmitt AB, Noth J, Nacimiento W (1998) Spontaneous longitudinally orientated axonal regeneration is associated with the Schwann cell framework within the lesion site following spinal cord compression injury of the rat. J Neurosci Res 53:51-65.
Chuah MI, West AK (2002) Cellular and molecular biology of ensheathing cells. Microsc Res Tech 58:216-227.

Devon R, Doucette R (1992) Olfactory ensheathing cells myelinate dorsal root ganglion neurites. Brain Res 589:175-179.

Doucette R (1991) PNS-CNS transitional zone of the first cranial nerve. J Comp Neurol 312:451-466.

Franklin RJ, Gilson JM, Franceschini IA, Barnett SC (1996) Schwann celllike myelination following transplantation of an olfactory bulbensheathing cell line into areas of demyelination in the adult CNS. Glia 17:217-224.

Graziadei PP, Levine RR, Graziadei GA (1978) Regeneration of olfactory axons and synapse formation in the forebrain after bulbectomy in neonatal mice. Proc Natl Acad Sci USA 75:5230-5234.

Honmou O, Felts PA, Waxman SG, Kocsis JD (1996) Restoration of normal conduction properties in demyelinated spinal cord axons in the adult rat by transplantation of exogenous Schwann cells. J Neurosci 16:3199-3208.

Huang H, Chen L, Wang H, Xiu B, Wang R, Zhang J, Zhang F, Gu Z, Li Y, Song Y, Hao W, Pang S, Sun J (2003) Influence of patients' age on functional recovery after transplantation of olfactory ensheathing cells into injured spinal cord injury. Chin Med J (Engl) 116:1488-1491.

Imaizumi T, Lankford KL, Waxman SG, Greer CA, Kocsis JD (1998) Transplanted olfactory ensheathing cells remyelinate and enhance axonal conduction in the demyelinated dorsal columns of the rat spinal cord. J Neurosci 18:6176-6185.

Imaizumi T, Lankford KL, Kocsis JD (2000a) Transplantation of olfactory ensheathing cells or Schwann cells restores rapid and secure conduction across the transected spinal cord. Brain Res 854:70-78.

Imaizumi T, Lankford KL, Burton WV, Fodor WL, Kocsis JD (2000b) Xenotransplantation of transgenic pig olfactory ensheathing cells promotes axonal regeneration in rat spinal cord. Nat Biotechnol 18:949-953.

Kato T, Honmou O, Uede T, Hashi K, Kocsis JD (2000) Transplantation of human olfactory ensheathing cells elicits remyelination of demyelinated rat spinal cord. Glia 30:209-218.

Keyvan-Fouladi N, Li Y, Raisman G (2002) How do transplanted olfactory ensheathing cells restore function? Brain Res Brain Res Rev 40:325-327.

Keyvan-Fouladi N, Raisman G, Li Y (2003) Functional repair of the corticospinal tract by delayed transplantation of olfactory ensheathing cells in adult rats. J Neurosci 23:9428-9434.

Lakatos A, Smith PM, Barnett SC, Franklin RJ (2003) Meningeal cells enhance limited CNS remyelination by transplanted olfactory ensheathing cells. Brain 126:598-609.

Lankford KL, Imaizumi T, Honmou O, Kocsis JD (2002) A quantitative morphometric analysis of rat spinal cord remyelination following transplantation of allogenic Schwann cells. J Comp Neurol 443:259-274.

Li Y, Field PM, Raisman G (1997) Repair of adult rat corticospinal tract by transplants of olfactory ensheathing cells. Science 277:2000-2002.

Li Y, Field PM, Raisman G (1998) Regeneration of adult rat corticospinal axons induced by transplanted olfactory ensheathing cells. J Neurosci 18:10514-10524.

Lu J, Feron F, Mackay-Sim A, Waite PM (2002) Olfactory ensheathing cells promote locomotor recovery after delayed transplantation into transected spinal cord. Brain 125:14-21.

Namiki J, Kojima A, Tator CH (2000) Effect of brain-derived neurotrophic factor, nerve growth factor, and neurotrophin-3 on functional recovery and regeneration after spinal cord injury in adult rats. J Neurotrauma 17:1219-1231.

Neumann S, WoolfCJ (1999) Regeneration of dorsal column fibers into and beyond the lesion site following adult spinal cord injury. Neuron 23:83-91.

Plant GW, Christensen CL, Oudega M, Bunge MB (2003) Delayed transplantation of olfactory ensheathing glia promotes sparing/regeneration of supraspinal axons in the contused adult rat spinal cord. J Neurotrauma 20:1-16.

Radtke C, Akiyama Y, Brokaw J, Lankford KL, Wewetzer K, Fodor WL, Kocsis JD (2004) Remyelination of the nonhuman primate spinal cord by transplantation of H-transferase transgenic adult pig olfactory ensheathing cells. FASEB J 18:335-337.

Ramer LM, Au E, Richter MW, Liu J, Tetzlaff W, Roskams AJ (2004) Peripheral olfactory ensheathing cells reduce scar and cavity forma- 
tion and promote regeneration after spinal cord injury. J Comp Neurol 473:1-15.

Ramon-Cueto A, Avila J (1998) Olfactory ensheathing glia: properties and function. Brain Res Bull 46:175-187.

Ramon-Cueto A, Plant GW, Avila J, Bunge MB (1998) Long-distance axonal regeneration in the transected adult rat spinal cord is promoted by olfactory ensheathing glia transplants. J Neurosci 18:3803-3815.

Ramon-Cueto A, Cordero MI, Santos-Benito FF, Avila J (2000) Functional recovery of paraplegic rats and motor axon regeneration in their spinal cords by olfactory ensheathing glia. Neuron 25:425-435.

Senior K (2002) Olfactory ensheathing cells to be used in spinal-cord repair trial. Lancet Neurol 1:269.
Takami T, Oudega M, Bates ML, Wood PM, Kleitman N, Bunge MB (2002) Schwann cell but not olfactory ensheathing glia transplants improve hindlimb locomotor performance in the moderately contused adult rat thoracic spinal cord. J Neurosci 22:6670-6681.

Warden P, Bamber NI, Li H, Esposito A, Ahmad KA, Hsu CY, Xu XM (2001) Delayed glial cell death following wallerian degeneration in white matter tracts after spinal cord dorsal column cordotomy in adult rats. Exp Neurol 168:213-224.

Woodhall E, West AK, Chuah MI (2001) Cultured olfactory ensheathing cells express nerve growth factor, brain-derived neurotrophic factor, glia cell line-derived neurotrophic factor and their receptors. Brain Res Mol Brain Res 88:203-213. 